\title{
IMPACT OF MICRONUTRIENTS AND HYGIENE ON THE FIGHT AGAINST PANDEMIC, ITS ROLE IN THE OVERALL HEALTH OF ADOLESCENTS FROM UNDERPRIVILEGED FAMILIES
}

\author{
DR. NUTAN BALA
}

Faculty Member, P.G.T +2 High School, Barkagaon, Muzaffarpur, BiharEx Researcher, LNMU Darbhanga

\begin{abstract}
The aim of the research was to evaluate the effect of micronutrients and hygiene on the health and overall nutritional situation of adolescents. The research revolves around micronutrient supplementation and its distribution amongst adolescents, the availability of bio-fortified food products to the children belonging to the underprivileged families and also the routine hygiene practiced by them. Special emphasis was laid on the effect of the micronutrient status in the meal and hygiene practices; the way these factors prepare a child to fight against a pandemic. A total of a 5 essential micronutrients, including 2,503 participants assessing the impact of micronutrients on their health were included in this research. The frequency of regular hygiene routine was examined among the participants and was analysed accordingly. Adolescents were purposely selected from the underprivileged sections of the society, the ones which hail from poor social and economic backgrounds, as the children belonging to such families is are unable to avail the basic nutritional benefits and are unaware of the essential hygiene practices, especially during pandemic outbreaks. Among the outcomes, a significant effect of micronutrients such as Iron, Calcium and Zinc was found on the health of adolescents. A few traditional medicinal herbs such as Glycirrhizin and Andrographis paniculata were also found to have a pronounced effect prevention against pandemics. The significance of healthy hygiene practices were thoroughly assessed and showed direct impact on prevention against pandemic.
\end{abstract}

KEYWORDS: Pandemic, Micronutrients, Adolescent Health \& Hygiene Bio-Fortification

Received: Sep 13, 2020; Accepted: Oct 03, 2020; Published: Oct 28, 2020; Paper Id.: IJHRMRAUG202010

\section{INTRODUCTION}

It is seen globally that the population of adolescent children is remarkably significant. In Asia, approximately more than 50 percent of population comprises of adolescents. In actual count, more adolescents are living in South Asiathat too about 350 million-which is greater than any other continent. About 21\% of Indian population is adolescent (about 243 million). Adolescence is a crucial stage of life as most of the harmful causes, both for communicable and non-communicable diseases tend to arise during this period, and attacking adolescents, especially from underprivileged family backgrounds can pose serious threats to the society during pandemic outbreak. Micronutrient deficiency and failure of following the hygiene practices have emerged as an important concern regarding public health. Also, the advancement is prejudiced as the families with poor socio-economic development carry a higher burden of diseased adolescent's compared to the children coming from well-off families.

Nutrition is a critical part of health and development of an adolescent. And micronutrients, though in minute quantities, but play a major role in shaping a good health and immunity of a child. Any nutritional 
deficiency experienced during these crucial years of life can have a drastic effect on the future health of the individual and their offspring in combating harsh situations of pandemics. Adolescents hailing from poverty - stricken families are eating less than prescribed intake of vegetables and fruits, and precariously high levels of sugar and sodium. As a per the findings of the present investigation assessing dietary intake practices among adolescents coming from poor families suggested that less than half of the children proclaimed consuming dairy products, fruits and vegetables. Unfortunately, the ones who did include micronutrients in their diet, failed to fulfil the dietary guidelines given by the World Health Organization (WHO); thereby becoming potential victims of pandemic outbreak.

Hygiene and safe sanitation play a significant role in preventing deadly diseases and living a healthy and fulfilling life. However, it has become a forgotten development issue, especially among the children belonging from poor families. Most of them still lack a basic hand-washing facility in their home and a lot of them lack a basic hygiene service at their schools. Worsening facts and figures indicate a dangerous threat to such children during pandemic. The present investigation has been conducted to find the effect and consequences of micronutrients and hygiene on the health of adolescents from underprivileged families in the times of pandemic outbreak.

\section{IMPORTANCE OF THE STUDY}

Amidst the harsh times of pandemic spread, when the whole world is struggling towards leading a safe and sustainable lifestyle, awareness about nutritional status and hygiene practices has become the need of the hour. There are many underprivileged adolescents who are scarce of immunological capacity, some are suffering due to lack of resources, and rest of them are struggling with a lack of resolve. Therefore, it is necessary to review the significance and impact of hygiene and micronutrients on adolescent's health as per the present investigation.

\section{OBJECTIVES OF THE STUDY}

- To assess the five essential micronutrients in terms of the nutritional benefits provided by them.

- To group the participants based on the type of micronutrient-intake in their diets.

- To study the impact of hygiene practices followed by the participants at home and school.

- To develop a framework inclusive of the effects of both micronutrients and hygiene on the comprehensive health of participants during pandemic.

\section{Hypothesis}

There is a significant association between micro-nutrient intake and hygiene practices on adolescent's health which prepare them to sustain during pandemic outbreaks.

\section{METHODOLOGY}

The subjects in the study were adolescents (10-19 year old), whose homes were visited and dietary and sanitation hygiene were evaluated.

\section{Definition}

- PANDEMIC - A pandemic is a situation of epidemic that occurs globally and crosses all international boundaries, severely affecting a large share of the global population. Pandemic can also take place in commercial 
organisms of agricultural importance (livestock, crop plants, fish, tree species) or in other organisms. The root cause of a pandemic spread cannot be sufficed to the fact that it lethal for people and it is widespread: a pandemic must also be contagious.

- MICRONUTRIENTS - Micronutrients are elements of major significance needed by organisms in various quantities throughout their life to manage a range of physiological functions to maintain health. The requirements of micronutrients differ among organisms; for example, humans and other animals need a number of vitamins and minerals for dietary intake, whereas plants require only some specific minerals. In human nutrition, micronutrients required are less than $100 \mathrm{mg}$ per day, whereas nutrients are needed in gram quantities daily.

- ADOLESCENT HEALTH - Adolescent health, or youth health is an inclusive term which deals with the various approaches towards detecting, preventing or treating the health and well being of young people. Adolescent health is often complex and thus asks for a biopsychosocial and comprehensive approach.

- HYGIENE - Hygiene refers to a number of practices established to protect and secure good health. As per the World Health Organization (WHO), "Hygiene refers to condition and practices that help to maintain health and prevent the spread of diseases". Personal hygiene entails maintaining cleanliness of the body. The terms hygiene and cleanliness are used synonymously by most people, however hygiene is a vast term. It is inclusive of certain choices of personal habits as how frequently to take a bath or shower, wash clothes, trim fingernails, and wash hands. It also emphasises to keeping our surroundings clean and free from pathogens, be those surfaces in the home and workplace, inclusive of the bathroom facilities, etc.

- BIOFORTIFICATION- Biofortification entails the method of crop breeding to enrich their nutritional content of food. This can be achieved either through genetic engineering or through conventional selective breeding. Biofortification and ordinary fortification are different as the former aims on raising the bar for nutritional value right when the plants are in their growth phase, rather than adding nutrients to the food during processing. This is a significant modification on ordinary fortification when we have to provide nutrients for the adolescents living in poor families and rural areas, who have negligible access to bio-fortified foods. Hence, biofortification can be considered as a boon for coping with micronutrients' deficiency among the adolescents coming from underprivileged families.

\section{Micronutrients}

- ZINC: Zinc is considered as an important mineral which is present naturally in certain foods, and also sold as a dietary supplement. It is an important micronutrient for growth and development, immunological functions, and reproduction. 


\section{Functions of Zinc}

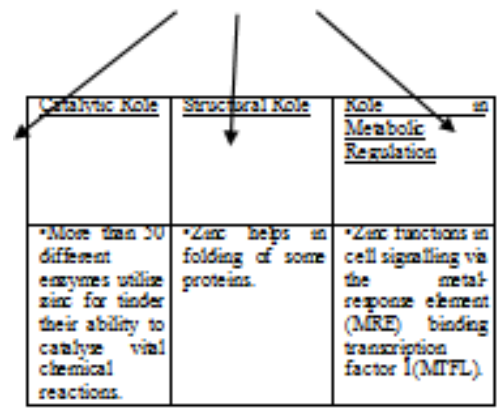

\begin{tabular}{|c|c|c|}
\hline Gank ROA & SYrot:xaROA & $\frac{\text { Roge }}{\text { Matbole }}$ \\
\hline 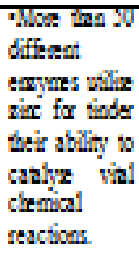 & 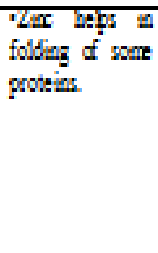 & 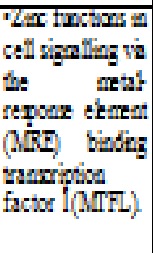 \\
\hline 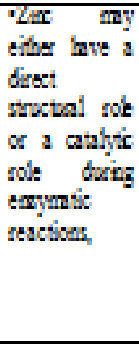 & 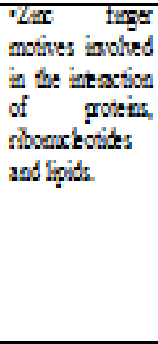 & 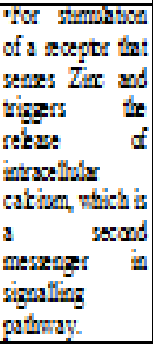 \\
\hline & 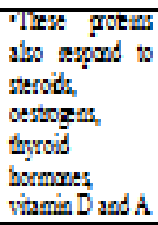 & \\
\hline
\end{tabular}

Immunity Booster - Zinc keeps the skin healthy, which prevents foreign invaders from entering the body. Zinc's is essential because it regulates the immune system and is responsible for antimicrobial activity. Supplementation of zinc not only increases white blood cell counts in zinc-deficient adolescents but also increases the immune response in healthy adolescents. Its consumption has been reported to inhibit various viral replication, thereby providing protection during serious pandemic outbreaks.

Table 1: Prescribed Allowances for Zinc in Diet

\begin{tabular}{|l|l|l|}
\hline AGE & Male & Female \\
\hline $8-14$ years & $8 \mathrm{Mg}$ & $8 \mathrm{mg}$ \\
\hline $14-18$ years & $11 \mathrm{Mg}$ & $9 \mathrm{Mg}$ \\
\hline $19+$ years & $11 \mathrm{Mg}$ & $8 \mathrm{Mg}$ \\
\hline
\end{tabular}

The table given above gives a brief description of the recommended intake of Zinc in the regular diet of adolescents. 


\section{Vitamin-D}

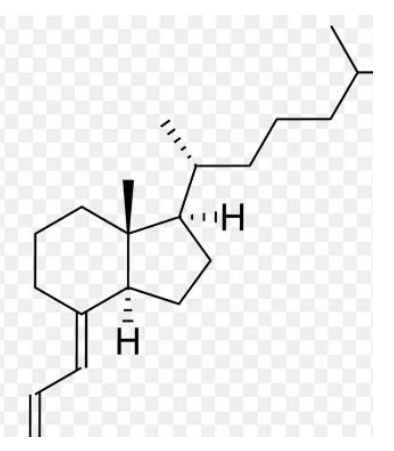

Figure 1

\section{Cholecalciferol}

Vitamin D is a salient regulator that finds its significance in the homeostasis of elements like calcium and phosphorus. It is also responsible for cell differentiation along with the secretion and metabolism of hormones including parathyroid hormone and insulin. Vitamin D (Cholecalciferol) is synthesized in the skin from its precursor, 7-dehydrocholesterol, by the action of sunlight.

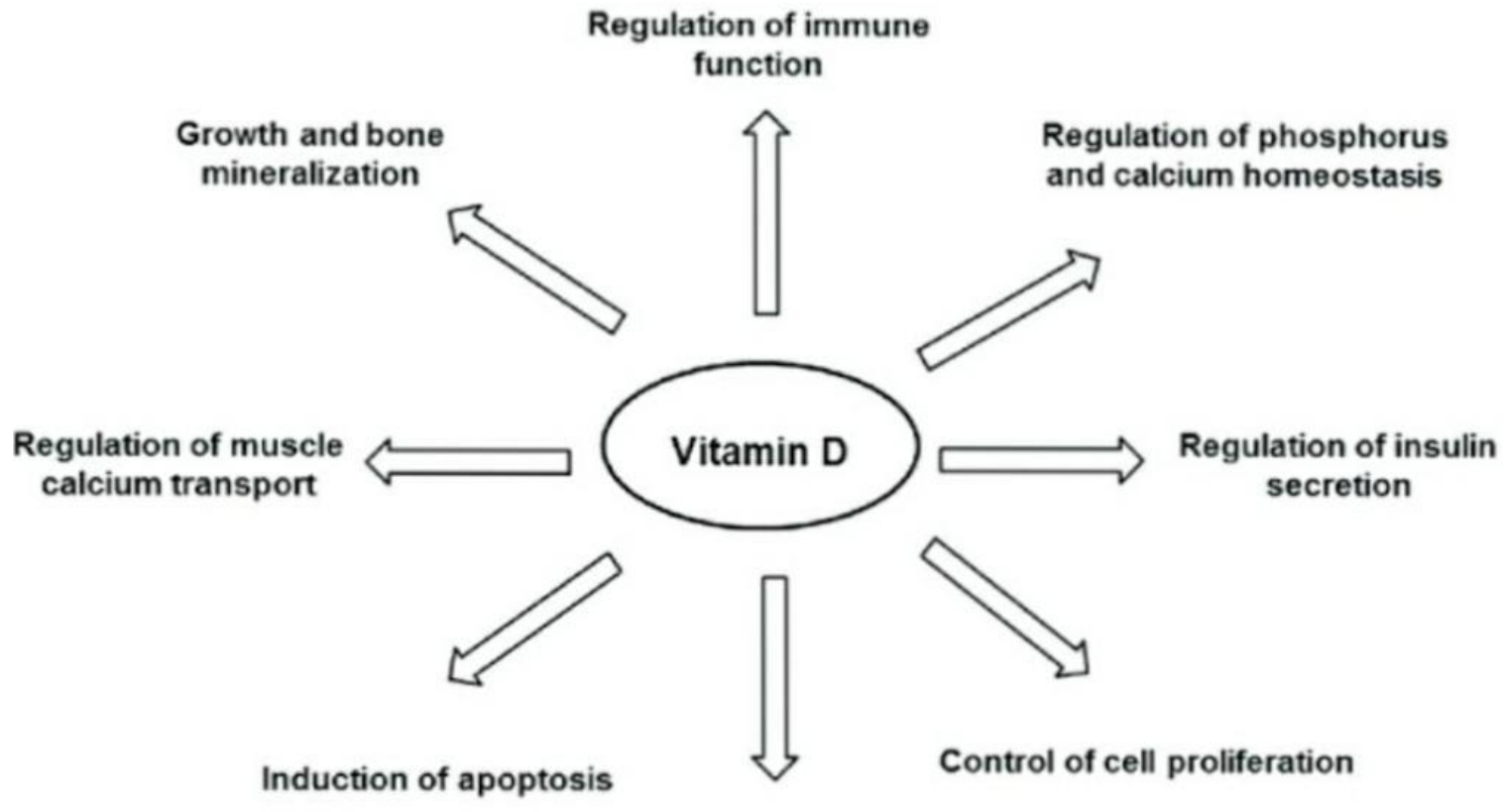

\section{Stimulation of cell differentiation}

Figure 2

Table 2: Prescribed Allowances for Vitamin D in Diet

\begin{tabular}{|l|c|c|}
\hline \multicolumn{1}{|c|}{ Age } & Male & Female \\
\hline $1-13$ years & $600 \mathrm{IU}(15 \mathrm{mcg})$ & $600 \mathrm{IU}(15 \mathrm{mcg})$ \\
\hline $14-18$ years & $600 \mathrm{IU}(15 \mathrm{mcg})$ & $600 \mathrm{IU}(15 \mathrm{mcg})$ \\
\hline
\end{tabular}

In the above listed table, intake allowances for vitamin D are listed in both International units (IUs) and micrograms (mcg); the biological activity of $40 \mathrm{IU}$ is equal to $1 \mathrm{mcg}$. 


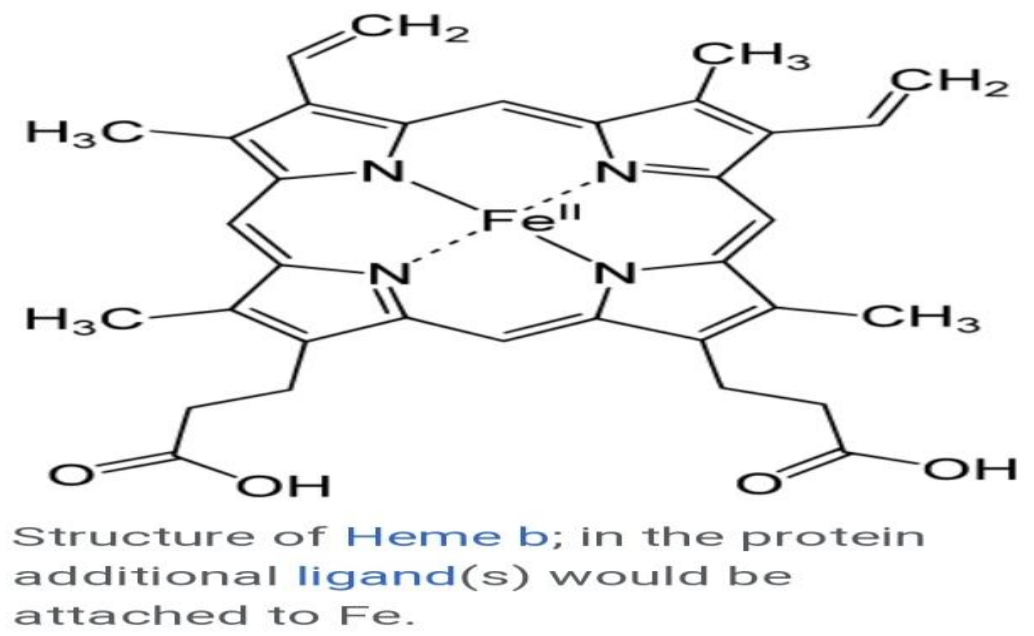

Figure 3

\section{Iron}

In human body, Iron is present in the red blood cells or the erythrocytes as a protein named haemoglobin, where its primary function is to carry oxygen from the lungs to the tissues. Iron is also an essential component of various enzyme systems, such as the cytochromes which are involved in oxidative metabolism. It is stored in the liver as ferritin and as haemosiderin.

Table 3: Iron Required in Diet of $97.57 \%$ of Adolescents on the Basis of the Iron Absorbed by Age Group and Sex (World HEALTH Group and Organisation, 1989)

\begin{tabular}{|l|c|}
\hline \multicolumn{1}{|c|}{ Age/Sex } & Mg/day \\
\hline 6-12 years & 1.17 \\
\hline 12-16 years & 2.02 \\
\hline 12-16 years & 1.82 \\
\hline
\end{tabular}

The above listed table indicates that the requirement of Iron is very high among adolescents, especially during the period of growth spurt. It is seen that girls have their growth spurt before menarche, although growth is not finished at that time. Whereas in boys, there is seen a significant increase in the mass and concentration of haemoglobin during puberty. In this phase, requirements of Iron raises to a level above the average iron requirements in menstruating adolescents.

\section{Glycyrrhizin /Black Liquorice}

Glycyrrhizin, commonly known as black liquorice is readily utilized for its anti-inflammatory, immune-stimulating, and anti-viral properties. In China, glycyrrhizin is used as an adjunct to current anti-viral therapy for hepatitis and HIV. During a pandemic outbreak, Glycirrhizin or Black Liquorice is reported to have increased the immunity of individuals prone to the outbreak.

- $\quad$ Andrographis paniculata: As a steroid and an essential facet in Ayurveda, Andrographis is an adjunct used mainly for its properties of immuno-stimulating. Various studies have acknowledged its potential to not only lower the time span of upper respiratory infections but also greatly reduce the severity of symptoms. Andrographis is important because of its ability to increase lymphocyte production. 


\section{Comparison: Micronutrient Supplementation \& Bio-fortification}

A total of 5 micronutrients from the present investigation (including 2 traditional medicinal herbs) appraised the effect of micronutrient supplementation/fortification. Three studies determined calcium/vitamin D supplementation, two studies determined iron supplementation with or without folic acid and four studies analysed zinc fortification.

An MMN fortified eatable was reported in one group whereas zinc supplement was reported in the other group. Zinc supplement was reported in one group and an iron supplement in other group.

Table 4: Effect of Iron Supplementation on the Immunity of Adolescents

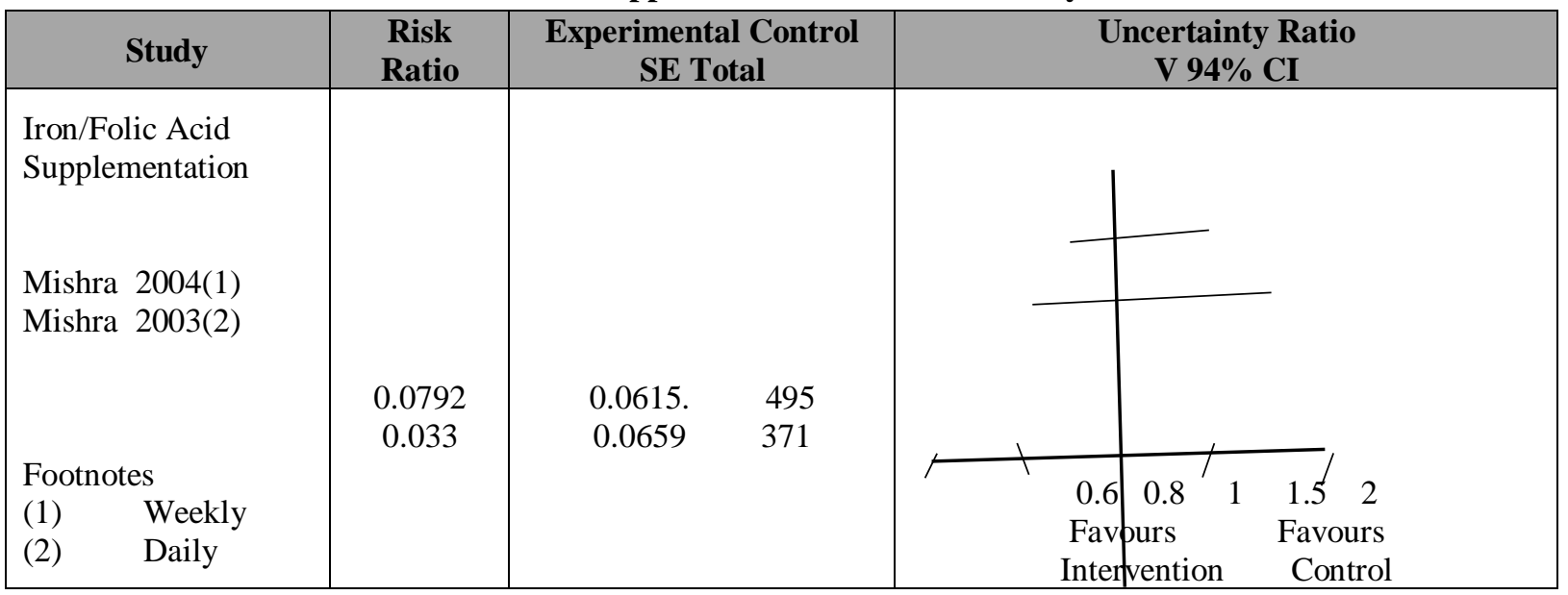

\section{Outcomes}

Supplementation of iron, either in presence or absence of folic acid may boost the haemoglobin levels in adolescents as when compared to a diet without fortification (MD: 032, 94\% CI0.12, 0.61; three studies; 1003 participants; I2 100\%; lowquality report). Calcium/vitamin D supplementation may lead to an increased level of serum $24(\mathrm{OH})$ D. Four studies reported the impact of zinc supplementation on the cognition of adolescents.

Table 5: Summary of Findings

\begin{tabular}{|c|c|c|c|c|c|}
\hline & $\begin{array}{l}\text { Interposition: Mic } \\
\text { Juxtapositio }\end{array}$ & $\begin{array}{l}\text { Subjects: Adolescents } \\
\text { Settings: Home } \\
\text { nutrient supplementation/Biof } \\
\text { No supplementation/ No fortific }\end{array}$ & $\begin{array}{l}\text { tification } \\
\text { tion }\end{array}$ & & \\
\hline Outcomes & $\begin{array}{c}\text { Presumed Risk } \\
\text { No Supplementation }\end{array}$ & $\begin{array}{c}\text { Corresponding Risk } \\
\text { Micronutrient } \\
\text { Supplementation/Fortification }\end{array}$ & $\begin{array}{c}\text { Relative } \\
\text { Effect } \\
(94 \% \mathrm{Cl}) \\
\end{array}$ & $\begin{array}{c}\text { No. of } \\
\text { Subjects }\end{array}$ & Grade \\
\hline $\begin{array}{l}\text { Iron } \\
\text { Supplementation } \\
\text { with or without } \\
\text { Folic Acid }\end{array}$ & 105 out of 465 & 115 out of 467 & RR 1.02 & 1003 & Low \\
\hline $\begin{array}{l}\text { Calcium/Vitamin } \\
\text { D } \\
\text { supplementation } \\
\text { on BMI }\end{array}$ & $\begin{array}{l}\text { Average BMI ranged } \\
\text { between } 18.13 \text { and } 18.4\end{array}$ & $\begin{array}{l}\text { Average BMI ranged between } \\
17.02 \text { and } 19=2\end{array}$ & $\begin{array}{l}\text { MD- } 0.02 \\
(1.3 \text { to } \\
1.16)\end{array}$ & 742 & $\begin{array}{l}\text { Very } \\
\text { low }\end{array}$ \\
\hline $\begin{array}{l}\text { Zinc } \\
\text { Supplementation } \\
\text { BMI }\end{array}$ & Average BMI was 16.22 & Average BMI was 16.56 & $\begin{array}{l}\mathrm{MD} 0.25(- \\
0.14 \text { to } \\
0.82)\end{array}$ & 362 & $\begin{array}{l}\text { Very } \\
\text { low }\end{array}$ \\
\hline $\begin{array}{l}\text { MMN } \\
\text { Fortification } \\
\text { BMI }\end{array}$ & $\begin{array}{l}\text { Average BMI ranged } \\
\text { between } 15.17 \text { and } 16.4\end{array}$ & $\begin{array}{l}\text { Average BMI ranged between } \\
15.32 \text { and } 17.2\end{array}$ & $\begin{array}{l}\text { MD } 0.21 \\
(-0.12 \text { to } \\
0.58)\end{array}$ & 928 & $\begin{array}{l}\text { Very } \\
\text { low }\end{array}$ \\
\hline
\end{tabular}


The tests for finding body mass index of adolescents from underprivileged families were conducted and the intake of essential micronutrients included in their diets were recorded. The observations suggested on increased value of BMI with micronutrient supplementation than those without any micronutrient supplementation.

\section{Hygiene}

Hygiene refers to a number of practices established to protect and secure good health. According to the World Health Organization(WHO), "Hygiene refers to conditions and practices that help to maintain health and prevent the spread of diseases. "Personal hygiene refers to maintaining the bodies' cleanliness."

- It is deemed that cleaning hands with soap and water could lower the numbers of deaths caused by diarrhoea by up to $50 \%$.

- A large chunk of food borne diseases are transmitted majorly by contaminated hands. Appropriate hand washing techniques can lower the chances of getting food borne illness and other infections.

Though it's paradoxical to wholly avoid airborne pathogens, there are few ways by which chances of infection can be reduced amongst adolescents -

- $\quad$ Stay away from people who have active symptoms of disease.

- Covering mouth during coughing or sneezing.

- Using handkerchief to cut down on the uncertainties of spreading germs on one's hands.

- Washing hands thoroughly (at least 20 seconds) especially after sneezing or coughing.

Table 6: Proportion of Adolescents Practicing Hand Wash Routines at their Homes at Critical Times by Gender.

\begin{tabular}{|c|c|c|c|c|}
\hline Critical times for Hand-Washing & $\operatorname{Total}(\%)$ & $\begin{array}{r} \\
\text { Girl } \\
\text { A }\end{array}$ & its & With \\
\hline Before preparing food & 58.6 & 72.6 & 34.3 & 63.1 \\
\hline Prior to serving food & 32 & 46.3 & 19.4 & 44.3 \\
\hline Prior to eating & 92.4 & 86.4 & 92.8 & 90.1 \\
\hline After defecation & 92.8 & 97.3 & 97.4 & 98.3 \\
\hline After any polluting activity & 60.4 & 65.6 & 52 & 63.9 \\
\hline
\end{tabular}

When enquired about the mediums that should be used to cleanse hands at various times, near about four-fifths $(82.3 \%)$ of the children approved of soap, accompanied by $8.7 \%$ who mentioned water only, and $5.9 \%$ who said sand and mud.

\section{CONCLUSIONS}

The review has appraised the effect of micronutrients and hygiene practices on adolescent's health and the way both the factors shape the immunity of adolescent children to combat serious pandemic outbreaks. Based on the findings of the research, it is concluded that a proper intake of the essential Micro-nutrients like Zinc, Iron,(with or without folic acid), vitamin D/ calcium and two traditional medicinal herbs - Glycyrrhizin and Andrographis paniculata can reduce the risk factors of adolescents getting infected in a pandemic outbreak. Routine hygiene practices followed by adolescents from underprivileged families too revealed that those who followed daily hygiene were less prone to getting diseased than those 
who did not do so. The hypothesis created in the beginning of the research that there is a significant association between micro-nutrient intake and hygiene practices on adolescent's health which prepares them to sustain during major pandemic outbreaks holds true.

\section{REFERENCES}

1. Keats, EC; Rappaport, A.I; Shah, S; oh, c; Jain, R; Bhutta, Z.A. The Dietary intake and Practices Adolescent girls in low Income countries: A Systematic Review. Nutrients 2018, 10, 1978.

2. Rajani, N., and G. Sireesha. "Micronutrient-Interaction among School Children."

3. Christian, P.; Smith, ER. Adolescent undernutrition; Global burden, physiology, and nutrition risks. Ann. Nutr. Metab. 2018, 72; 316-328.

4. Kianfax, H;; Kimiagar, M.; Ghaffarpour, M. Effect of daily and intermittent iron supplementation on status of high school girls. Int J. Vitam. Nutr. Res. 2000, 70, 172-177.

5. Sunitha, N., et al. "Assessment of Vark Learning Style Compatibility in Ict Modules on Health and Nutrition Education." International Journal of Educational Science and Research (IJESR) 7. 5, Oct 2017, 117-122

6. Prentice, A; Ginty, F; Stear, SJ.; Jones, S.C,, Laskey, M.A; Cole, T.J. Calcium Supplementation increases stature and bone mineral mass of 16 to 18- year old boys. J. Clin. Endocrinal Metab, 2005, 90, 3153-3161.

7. Akinlolu, Ajani R., et al. "Nutrient Compositions and Zinc-Bioavalability Estimation (In-Vitro) of the Edible Tropical Cereals." International Journal of Applied and Natural Sciences 3.5 (2014): $71-78$.

8. World Health Organisation Guideline : Intermittent Iron Supplementation in Preschool and School-age Children. Geneva; 2011.

9. Institute of Medicine, food and Nutrition Board. Dietary Reference Intakes for Calcium and Vitamin D. Washington DC: National Academy Press, 2010.

10. Sharma, Vishakha, and Vishakha Singh. "Impact of Education Intervention on Nutrition Knowledge of Adolescent Girls." International Journal of Applied and Natural Sciences (IJANS) 6.5, Aug - Sep 2017; 117-122

11. Solomons NW. Mild human zinc deficiency produces imbalance between cell mediated and humoral immunity. Nutr. Rev 1998; 56:27-8.

12. World Health Organisation - Health for the World's Adolescents: A Second Chance in the Second Decade: Summary; World Health Organization Geneva, Switzerland, 2014. 
